\title{
Investigation of the Properties of Polycarbonate Filled with Short Glass Fiber
}

\author{
Mustafa Gamal Sadek \\ Operation and Maintenance Engineer \\ Qena Paper Industry Company (QPIC) \\ Qena, Egypt. \\ mustafagamal539@yahoo.com
}

\author{
Montasser Dewidar \\ Mech. Design and Prod. Eng. Dept., \\ Faculty of Engineering, \\ Kafr ELsheikh University, \\ Kafr ELsheikh, Egypt. \\ dewidar5@hotmail.com
}

\author{
Ayman M.M. Abdelhaleem \\ Mech. Design and Prod. Eng. Dept., \\ Faculty of Engineering \\ Zagazig University, \\ Zagazig, Egypt. \\ aymanmns@hotmail.com
}

\begin{abstract}
The main objective of this research is to study the effect of adding short glass fiber (SGF) to pure polycarbonate (PC) using the injection molding process. The short glass fiber was mixed mechanically with $\mathrm{PC}$ in $5 \%, 10 \%$, and $15 \%$ by weight. The mechanical properties of pure polycarbonate reinforced with short glass fiber were investigated using tensile, and hardness tests. The wear resistance of the composites were investigated. The results showed that, by adding 5\%, $10 \%, 15 \%$ wt. of short glass fiber to the pure polycarbonate, the ultimate tensile strength increased from $66 \mathrm{~N} / \mathrm{mm}^{2}$ for neat polycarbonate to $73 \mathrm{~N} / \mathrm{mm}^{2}$ (i.e. $10.60 \%$ ), $75 \mathrm{~N} / \mathrm{mm}^{2}$ (i.e. $13.63 \%$ ), $78 \mathrm{~N} / \mathrm{mm}^{2}$ (i.e. $18.18 \%$ ), respectively. The modulus of elasticity increased to 2041MPa (13.38\%), $2350 \mathrm{MPa}(30.55 \%$, and to $2600 \mathrm{MPa}$ $(44.44 \%)$ when adding $5 \%$ SGF, $10 \%$ SGF, and $15 \%$ SGF to the $\mathrm{PC}$ respectively. The hardness test results, using shore $D$ tester, showed that, as the SGF particles contents were increased, the hardness increased from 83 for the PC, to 84, and 86 for $P C$ with SGF particles contents of $10 \%$, and $15 \%$ wt respectively. And no effect in case of $5 \%$ SGF. The wear test results showed that, at (500 $\mathrm{g}$ applied load, $25 \mathrm{~m}$ displacement, $V=34 \mathrm{~mm} / \mathrm{s}$; i.e speed) the weight loss increased at $5 \%$ SGF, then it decreased at $10 \%$, finally it rises again at $15 \%$ compared with pure PC. Scan Electronic Microscopy (SEM), showed that, a good interlock and interference between the SGF particles and the pure polycarbonate.
\end{abstract}

Keywords-Polycarbonate; Short glass fiber; Injection molding process; Mechanical properties; Wear resistance

\section{INTRODUCTION}

Polycarbonate (PC), an engineered thermoplastic polymer, possesses excellent temperature resistance, optical transparency, high impact strength, good optical properties, and dimensional stability [1]. Hence, it is widely used in automotive industry, components of aircraft, electronics, data storage, and biomedical devices such as hemodialyzers, drug delivery carriers, blood oxygenators, and arterial filters [2].

In order to improve the mechanical properties of polymer composites, E-glass fibers are most commonly reinforced into the polymer matrix. The major problem associated with the untreated E-glass fibers is that they exhibit low interfacial adhesion between the fibers and thermoplastic matrix. This can be overcomed by treating the surface of E-glass fiber with 3Aminopropyltriethoxy (3-APE) silane coupling agent [3-6].
Now-a-days, fiber reinforced polymer (FRP) composites are widely used in the medical field, where the mechanical properties are a serious concern [7]. The conventional metallic/ceramic orthopedic implants are being replaced by FRP composites. The advantage of using FRP composites in load bearing orthopedic implants is mainly because of their light weight, high strength and stiffness than the conventional metallic implants. This will reduce the "stress shielding' effect around the implants [8]. They exhibit high biocompatibility, non-corrosion and good bonding between the bone and implant [9-11].

Many researchers have already done a good amount of work in the subject of investigation of properties of polycarbonate. Manjunath [12] worked on mechanical properties testing of glass reinforced polycarbonate. Surface hardness measurements by Shore schelorescope method revealed that the hardness values varied between 87 and 93 and tensile strength varied between 80 and $107 \mathrm{MPa}$.

Abdulkadir et al [13] reported that during tensile testing of the reinforced plastics, the load applied to the matrix transferred to the glass fibers. They stated that, in order to improve the strength of the composites, a strong interface bonding between the fibers and plastic is required. They also observed that the humidity reduces the bonding force between the plastic and reinforcement element. Chuan et al [14] observed that, GFRPP shows good resistance against acid and salt solutions but bad resistance against alkali solutions. Ota et al [15] studied the combined effect of injection temperature and the fiber content on the properties of the polypropyleneglass fiber composites. They concluded that the tensile strength and the elastic modulus decreased with the increase of the injection temperature, and that the melt flow index of the composites depend upon fibers content, fibers length and distributions. The tensile strength and elastic modulus increased with increasing the fiber contents. Bajracharya et al [16] studied experimentally and theoretically the properties of injection molded glass fiber reinforced mixed plastic composites. They found that, with the addition of $30 \mathrm{wt} \%$ of glass fiber, the strength properties and elastic modulus increased by as much as $141 \%$ and $357 \%$, respectively. The 
best improvement was seen in the flexural properties due to the better orientation of the glass fibers in the longitudinal direction at the outer layers.

Ozaki et al [17] analyzed the effect of the hot-press parameters on the bending properties of a $\mathrm{CF} /$ polycarbonate (PC) laminate, and Tanaka et al [18] investigated the interfacial bonding strength and the inter laminar shear strength of this laminate. They suggested that an optimal hotpress temperature should be set at approximately $300^{\circ} \mathrm{C}$ and 6 MPa pressure accompanied by sufficient holding time (half an hour of whole hot-press process or several minutes of maximum temperature) to obtain secure $\mathrm{CF} / \mathrm{PC}$ interfacial bonding. Qian et al [19] researched the effect of polycarbonate film surface morphology and oxygen plasma treatment on mechanical properties of composite laminates. They selected relatively low temperature at $180^{\circ} \mathrm{C}$ to fabricate laminates, which at cost of 2 times of hot-press one. Even in the fabrication of carbon nanotube/pc composite, Choi et al [20] set melting temperature of twin extruder at $300^{\circ} \mathrm{C}$.

It may be concluded from the above discussion that the investigation of properties of polycarbonate is utilized to examine and better understand the properties of PC and to identify and evaluate possible process modifications to improve the properties of pc. The main objective of this study is to investigate the properties of polycarbonate / short glass fiber blends.

\section{EXPERIMENTAL WORKS}

\section{A. Materials and Characterization}

The PC used in this work was supplied by SABIC from Egyptian market (PC1003R resin) with density of 1.2

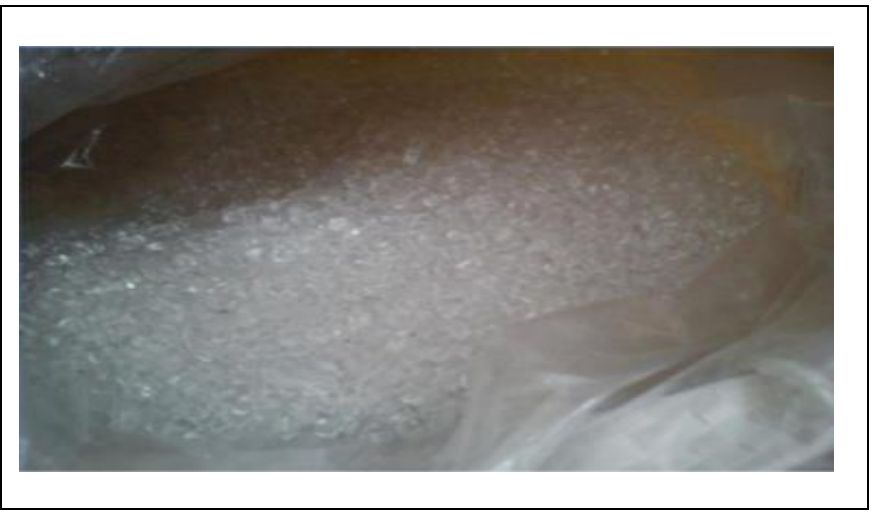

Fig. 1. Photo picture of the raw material of polycarbonate.

$\mathrm{g} / \mathrm{cm}^{3}$ (specific gravity $\left.=1.2\right)$, Water Absorption $\left(23^{\circ} \mathrm{C}\right.$ $/ \mathrm{sat})=0.35 \%$ according to ISO 62 , Melt Volume Rate(MVR) at $300^{\circ} \mathrm{C} / 1.2 \mathrm{~kg}=9 \mathrm{~cm}^{3} / 10 \mathrm{~min}$ ( ISO 1133), Refractive Index $=1.586$ according to ASTM D 542 .

Glass fibers used in present work; Fig.1, was E6 and was supplied by Jushi co. Ltd. [21] had diameter of 40 micron and was cut and dispersed for lengths of $10-20 \mathrm{~mm}$, and its density $2.6 \mathrm{~g} / \mathrm{cm}^{3}$; as shown in Fig. 2 .

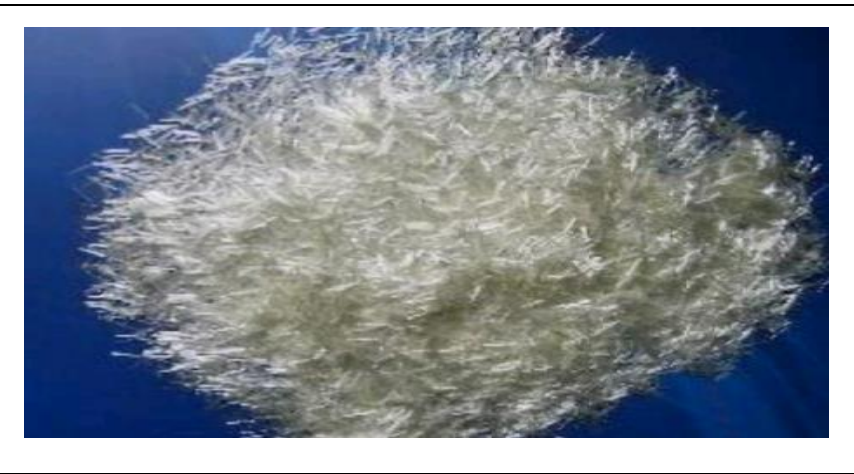

Fig. 2. Photo picture of the raw material of short glass fiber.

\section{B. The Mold}

Plastic injection mold for tensile, impact and wear test samples was designed and manufactured. The mold was checked many times to be suitable for producing the required test samples according to ASTM 638 [22]. In this mold, the direction of the flow of the plastic takes into account that it was in one direction for each sample to avoid any probability of producing weld lines which may cause weakness and hence cracking. Fig. 3. shows the plastic injection molding machine; HAITIAN-PL 1200 was used to produce the required test samples. The maximum clamping force is $1200 \mathrm{KN}$.

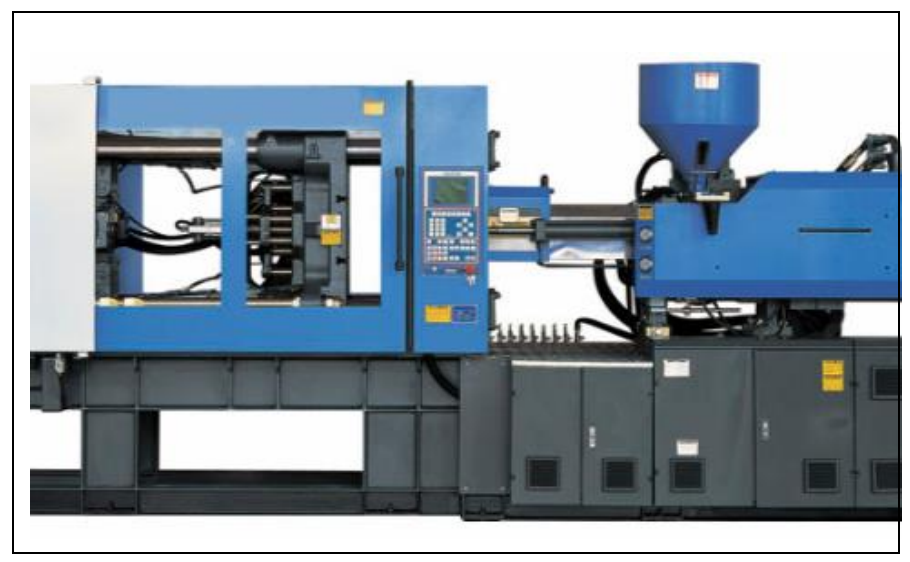

Fig. 3. The plastic injection molding machine (HAITIAN, PL 1200, 2010, South Korea).

Fig. 4. Shows the tensile test sample dimensions according to ASTM D638, $b=3.18 \mathrm{~mm}, L_{c}=9.53 \mathrm{~mm}, B=9.53$ $\mathrm{mm}, L=63.5 \mathrm{~mm}, L_{0}=7.62 \mathrm{~mm}$, and thickness; $a=3 \mathrm{~mm}$.

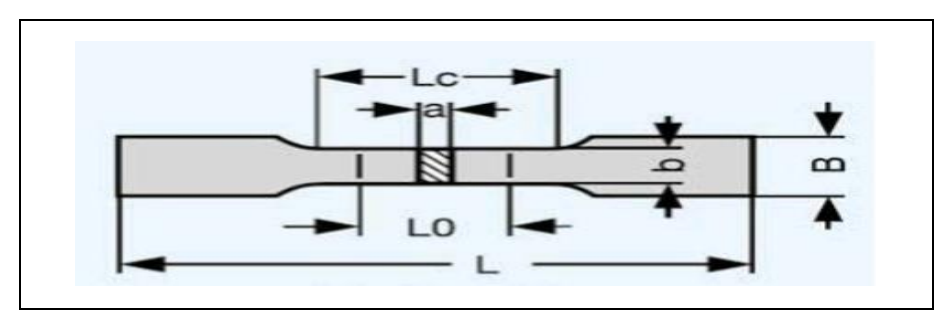

Fig. 4. Tensile test sample, $\left(b=3.18 \mathrm{~mm}, L_{c}=9.53 \mathrm{~mm}\right.$, and $\left.a=3 \mathrm{~mm}\right)$. 


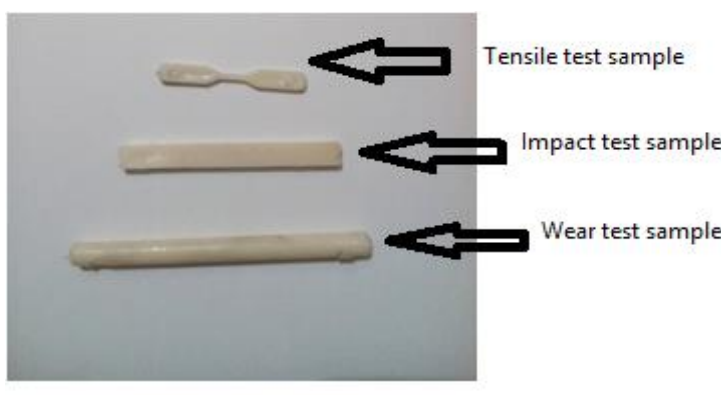

Fig. 5. Photograph of test samples (impact test sample, $W^{*} B=10 \mathrm{~mm} * 10 \mathrm{~mm}$ and $90 \mathrm{~mm}$ length), (wear test sample diameter; $D=10 \mathrm{~mm}, L=120 \mathrm{~mm}$ )

\section{Machines and Processing for Manufacturing}

To produce the test samples the plastic injection mold is mounted into the injection molding machine. Table 1 shows the operating temperatures to manufacture specimens.

The process may be described as follow:

Firstly: PC was dried at $120{ }^{\circ} \mathrm{C}$ for 3 hours in an air dryer before processing to avoid possible moisture degradation reactions.

Secondly: It was mechanically mixed with $(5,10,15) \%$ wt of SGF.

Thirdly: Mold was heated to $80{ }^{\circ} \mathrm{C}$ before injection according to PC data sheet of SABIC company then, feeding the extruder of the injection molding machine ( single screw extruder) was fed by the mixed composites to produce the test samples.

TABLE 1 The operating temperatures to manufacture specimens.

\begin{tabular}{|l|c|}
\hline Process conditions & Temp $\left({ }^{\circ} \mathbf{C}\right)$ \\
\hline Rear zone temp & $260-280$ \\
Middle zone temp & $270-290$ \\
Front zone temp & $280-310$ \\
Melt temp & $280-310$ \\
Mold temp & $80-110$ \\
\hline
\end{tabular}

Fourth: The produced test samples with its sprue and runners were crushed in a crusher forming small particles with identical sizes.

Fifth: the shredded particles were fed into the injection molding machine to produce the final test samples. The main reason behind these stages was to obtain good distribution of the SGF in the PC.

Photograph of tensile, impact, and wear test samples are obtained from injection molding and used to study the mechanical properties are shown in fig.5.

\section{Testing}

The tensile test was carried out using LLOYD tensile testing machine (The model: LRX plus) at a cross-head speed of $5 \mathrm{~mm} / \mathrm{min}$ at room temperature $\left(33^{\circ} \mathrm{C}\right)$. Three tensile specimens were tested for each reported value and the average value was taken. The charpy impact tests were carried out on un-notched specimens, $(10 \mathrm{~mm} * 10 \mathrm{~mm} * 90 \mathrm{~mm})$, using digital charpy impact tester at $33^{\circ} \mathrm{C}$. A mass of energy $15 \mathrm{~J}$ was utilized according to rectangular un-notched specimens. Also three samples were tested and the average value was reported. The effects of impact strength were obtained to the composite.

Hardness test was carried out by Durometer shore D according to ASTM D2240 at room temperature. Six points on specimen were tested and the average value was reported. A pin on the disc was used to carry out wear resistance. All samples were pressed against a rotating disc with surface roughness of (P1000) at room temperature, with disc speed of $57 \mathrm{rpm}$. The rotating disc served as a counter face and the stationery block served as the test specimen. At distance of $(25,50$, and 75$) \mathrm{m}$, the weight was measured before and after the test for each sample at variety of loads $(500,1000$, and $1500 \mathrm{~g})$ by using a digital balance with accuracy $10^{-3} \mathrm{~g}$. The gold coated composite specimens were scanned for electron image. The morphology was recorded for surfaces, at $35{ }^{\circ} \mathrm{C}$ temperature and 1 bar pressure. Scanning electron microscopy (SEM) (JEOL JSM.5500LV) was utilized. The morphologies of the reinforced specimens, operating at an accelerating voltage of $25 \mathrm{kV}$ were obtained.

\section{RESULTS}

\section{A. Results of Tensile Test}

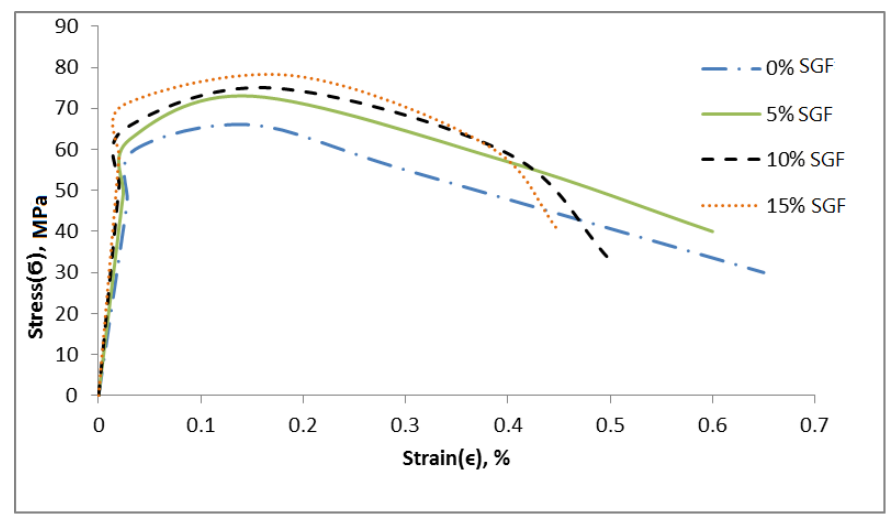

Fig. 6. variation of stress strain curves of (PC/S.G.F) blends.

Three samples of each of the required compositions to be tested were generated, pure PC and PC reinforced with different SGF contents of ratios, $5 \%, 10 \%$, and $15 \%$ wt. The average values of the results were calculated. Fig. 6 . shows the stress strain curves of the recycled polycarbonate with different amount of short glass fibers. It may be remarked that with the increase of SGF content in (PC/SGF) blends, the tensile strength increased. It may be concluded that young's modulus increased due to good adhesion between poly carbonate and short glass fiber particles. Test results revealed that nearly $13.38 \%$ improvement in young's modulus by adding 5\% of SGF to PC , 30.55\% improvement by adding $10 \%$ and $44.44 \%$ improvement by adding $15 \%$. Similar observation was also reported in [23] in which it is stated that the tensile strength and young's modulus of (PC/SGF) blends increased with the increase of SGF contents in (PC/SGF) blends. 


\section{B. Results of Impact Test}

Fig. 7. illustrates the variations of un-notched charpy impact strength of the PC/SGF composite. The maximum impact strength occurred to the pure PC sample was 170 $\mathrm{kJ} / \mathrm{m}^{2}$. The existing of SGF in the PC results in a significant reduction in the impact strength. It decreased from $170 \mathrm{~kJ} / \mathrm{m}^{2}$ for the pure PC to $150 \mathrm{~kJ} / \mathrm{m}^{2}$ for the PC with $15 \%$ SGF. So, it may be explained that the existing of the SGF in the composite resist the plastic deformation so the toughness gradually decreased.

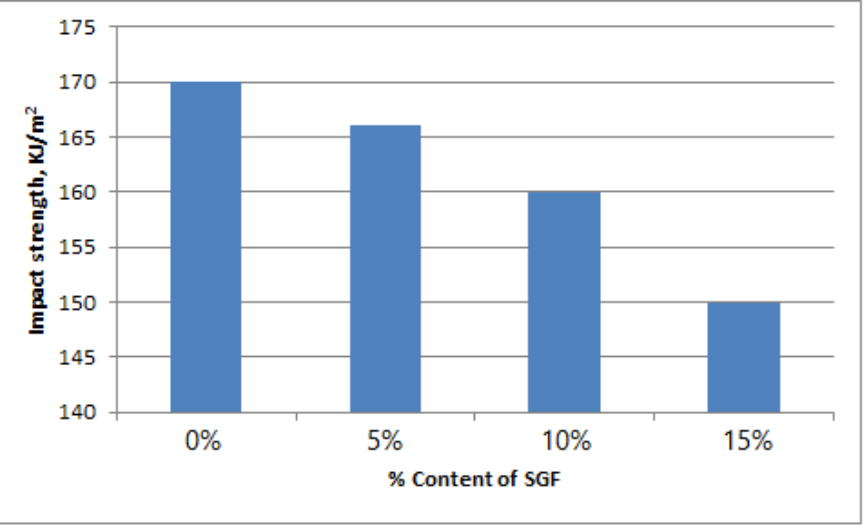

Fig. 7. variation of stress strain curves of (PC/S.G.F) blends.

\section{Results of Hardness Test}

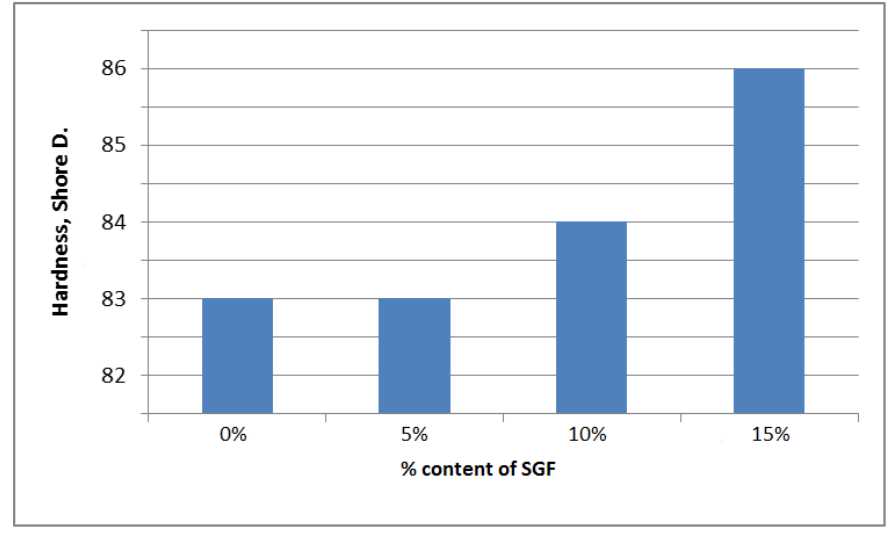

Fig. 8. variation of stress strain curves of (PC/S.G.F) blends.

The hardness was measured using shore D, Durometer and shown in Fig. 8. It may be noted that pure PC has 83 shore D. When adding 5\% SGF to PC, no change in the value of hardness, shore D was noticed. When adding $10 \%$ SGF to PC, the hardness became $84(1.2 \%)$. While adding $15 \%$ SGF to $\mathrm{PC}$, the hardness increased again to $86,(3.61 \%)$. This may be relied that the existing of SGF in the $\mathrm{PC}$ resists the plastic deformation and so made the composite more brittle. Similar observation was also reported in [23] in which it is stated that the hardness of (PC/SGF) blends increased with the increase of SGF contents in (PC/SGF) blends.

\section{Results of Wear Test}

The weight loss was calculated using pin on disc method, for each sample at travelling distances $25 \mathrm{~m}, 50 \mathrm{~m}$, and $75 \mathrm{~m}$ with speed; $V=34 \mathrm{~mm} / \mathrm{s}$, when using $500 \mathrm{~g}, 1000 \mathrm{~g}$, and $1500 \mathrm{~g}$ as applied loads as shown in Figs. 9 and 10.

TABLE 2 Wear test results of (PC/SGF) blends in gm.

\begin{tabular}{|c|c|c|c|c|}
\hline Weight, $\mathbf{g}$ & 0\% SGF & 5\% SGF & 10\% SGF & 15\% SGF \\
\hline 500 & 0.0204 & 0.0258 & 0.0234 & 0.0293 \\
\hline 1000 & 0.0290 & 0.0313 & 0.0278 & 0.0302 \\
\hline 1500 & 0.0493 & 0.0356 & 0.0321 & 0.0447 \\
\hline
\end{tabular}

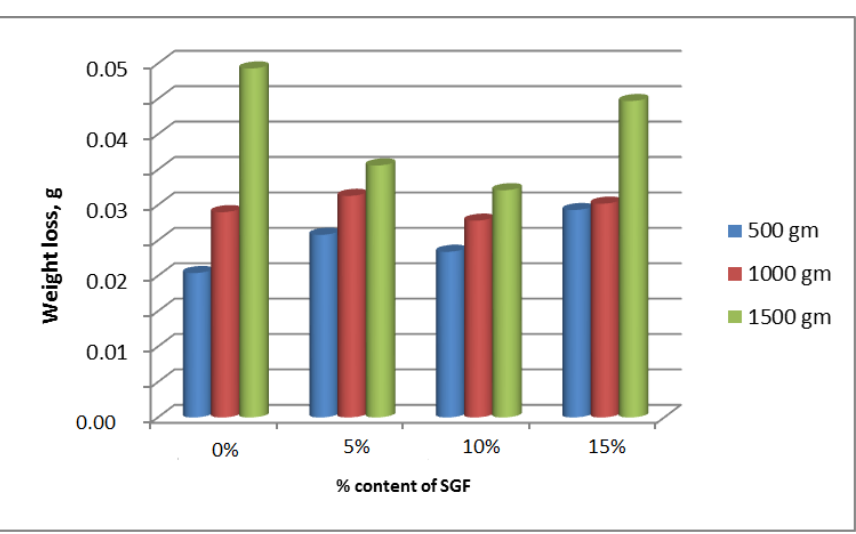

Fig. 9. Effect of SGF reinforced PC on the weight loss for $500 \mathrm{~g}, 1000 \mathrm{~g}$, and $1500 \mathrm{~g}$ at $25 \mathrm{~m}$ displacement; $V=34 \mathrm{~mm} / \mathrm{s}$.

TABLE 3 Wear test results of (PC/SGF) blends in $\mathrm{g}$

\begin{tabular}{|c|c|c|c|c|}
\hline Distance, $\mathbf{m}$ & 0\% SGF & 5\% SGF & 10\% SGF & 15\% SGF \\
\hline 25 & 0.0387 & 0.0417 & 0.0370 & 0.0403 \\
\hline 50 & 0.0420 & 0.0536 & 0.0505 & 0.0672 \\
\hline 75 & 0.0609 & 0.0640 & 0.0775 & 0.0786 \\
\hline
\end{tabular}

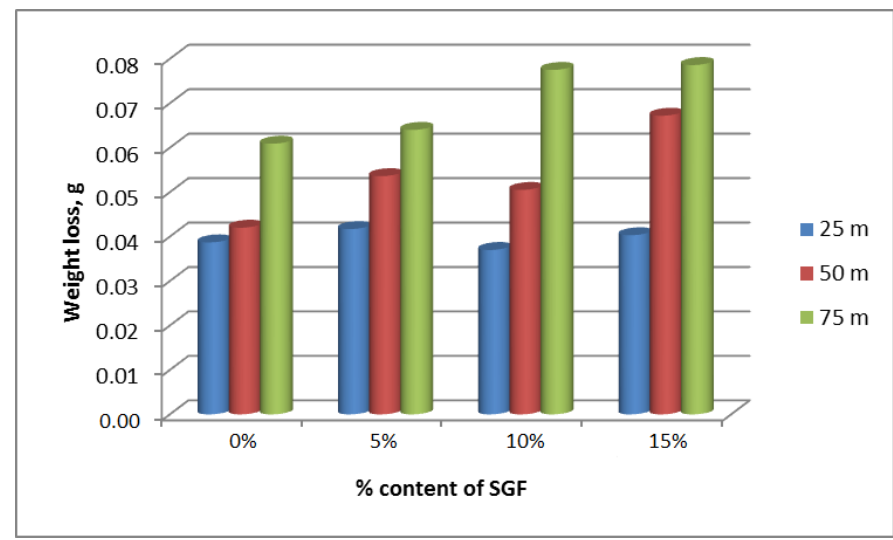

Fig. 10. Effect of SGF reinforced PC on the weight loss at displacement of $25 \mathrm{~m}, 50 \mathrm{~m}$, and $75 \mathrm{~m}$ with $1000 \mathrm{~g}$ weight, $V=34 \mathrm{~mm} / \mathrm{s}$. 
From Fig. 9, at 500g applied load. It may be observed that the weight loss increased at 5\% SGF, then it decreased at $10 \%$, finally it raised again at $15 \%$ compared with pure PC. At $1000 \mathrm{~g}$ applied load the weight loss increased at $5 \%$ SGF, then it decreased at $10 \%$, finally it increased again at $15 \%$ compared with pure PC. While at $1500 \mathrm{~g}$, the weight loss decreased at 5\% SGF, and continues decreasing at $10 \%$, finally it increased at $15 \% \mathrm{SGF}$.

From Fig. 10 at $25 \mathrm{~m}$; it may be observed that the weight loss increased at 5\% SGF, then it decreased at $10 \%$, finally it increased again at $15 \%$ compared with pure PC. At $50 \mathrm{~m}$; the weight loss increased at $5 \%$ SGF, then it reduced at $10 \%$ SGF, finally it increased again at $15 \%$ SGF, compared with pure PC. While at $75 \mathrm{~m}$, it gradually increasing by increasing the percentage of SGF, because of SGF particles, which come out of the composite and exist in the wear surface, lead to increase and speed up the wear rate.

\section{E. Microstructure of PolyCarbonate/Short Glass Fiber Composites (SEM)}

SEM was used for scanning the composite at different combinations $5 \%, 10 \%$ and $15 \%$ wt, of the SGF in the PC. In Fig. $11 \mathrm{a}, \mathrm{b}$, and c, it may be seen that the distribution of the SGF was good inside the PC. In Fig. $11-b$ and $c$, it may be shown that the extent of overlap of SGF in the PC. The irregular shapes of the SGF led to good interference among SGF and the PC. In Fig. 11 -c, at a concentration of $15 \%$ SGF in the PC, it may be noticed that the SGF is well distributed among the $\mathrm{PC}$. The improvement of the mechanical properties of the PC/SGF is due to the irregular shapes of the SGF.

Also the columns of glass fibers appear in the poly carbonate. These columns enhanced the mechanical properties of the composite.

\section{CONCLUSION}

a. With the increase of SGF content in (PC/SGF) blends, the tensile strength and young's modulus increased.

b. With the increase of SGF content in (PC/SGF) blends, the impact strength decreased gradually. So that SGF deteriorate the impact strength of (PC/SGF) blends.

c. With the increase of SGF content in (PC/SGF) blends, the hardness increased. With the increase of the content of SGF in PC from $0 \%$ to $5 \%$, there is no effect on hardness. With the increase of the content of SGF in PC from 5\% to $10 \%$, there is gradual increase in the hardness from 83 shore D to 84 shore D. There is a significant influence in hardness of the blends from $10 \%$ to $15 \%$ SGF content, the hardness increased from 84 shore D to 86 shore D.

d. The weight loss of (PC/SGF) blends decrease with the increase of SGF content so that SGF improves wear resistance of (PC/SGF) blends.

e. At $(500 \mathrm{~g}, 25 \mathrm{~m}$ displacement, $V=34 \mathrm{~mm} / \mathrm{s}$.) the weight loss increased at 5\% SGF, then it decreased at $10 \%$, finally it increased again at $15 \%$ compared with pure PC. f. A good interlock and interference between the SGF particles and the pure polycarbonate showed by SEM.

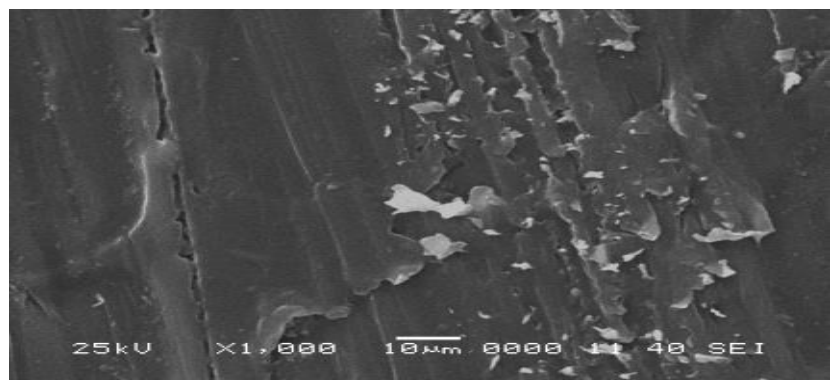

(a) $5 \% \mathrm{SGF}$.

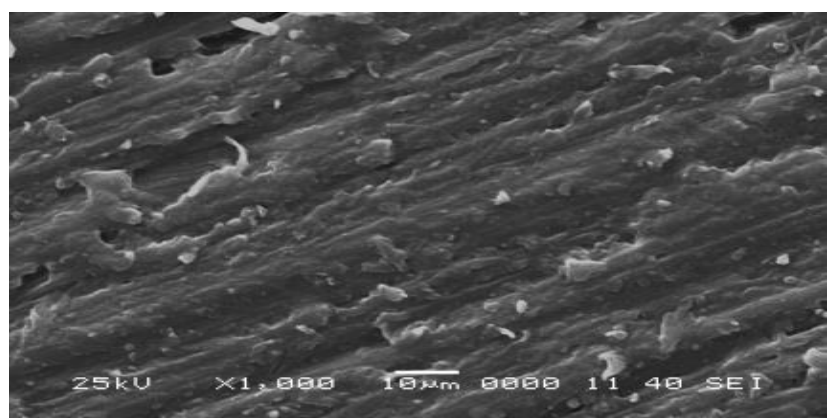

(b) $10 \% \mathrm{SGF}$

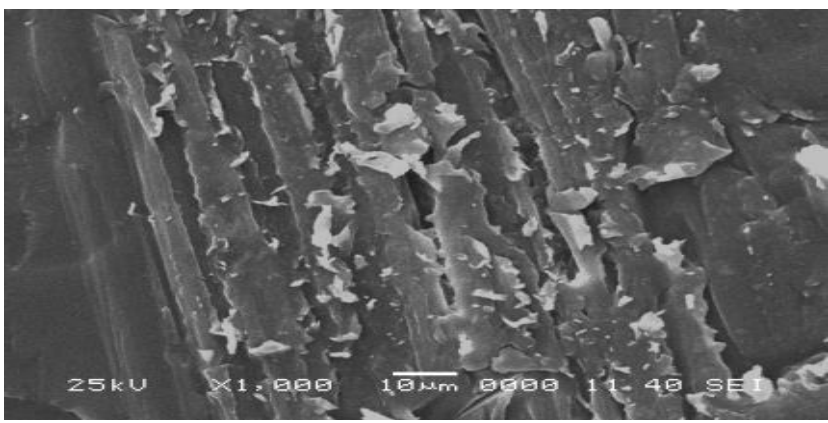

(c) $15 \% \mathrm{SGF}$

Fig. 11. SEM of different (PC/SGF) blends 


\begin{tabular}{ll}
\multicolumn{2}{l}{ Abbreviations. } \\
CF & Carbon Fiber \\
FRP & Fiber Reinforced Polymer \\
GFRPP & Glass Fiber Reinforced Polypropylene \\
kJ & Kilo joule \\
MPa & Mega Pascal \\
PC & Poly Carbonate \\
SEM & Scanning Electron Microscope \\
SGF & Short Glass Fiber
\end{tabular}

\section{Greek letter.}

$\epsilon$

Strain $(\%)$

6

Stress (MPa)

\section{REFERENCES}

[1] D. J. Brunelle and M. R. Korn. Advances in Polycarbonates, American Chemical Society, Washington, DC, USA, 2005.

[2] J. Xu, E. Feng, and J. Song. "Renaissance of aliphatic polycarbonates: new techniques and biomedical applications, "Journal of Applied Polymer Science, vol.131, no.5, Article ID 39822, 2014.

[3] Jacob, M.; Thomas, S. J. Appl. Polym. Sci. 93, 2305, 2004.

[4] Suardana, N. P. G.; Piao, Y.; Lim, J. K. Mater. Phys. Mech. 11, 1, 2011.

[5] Radojevic, V.; Stojanovic, D. Influence of Silane Coupling Agents on the Mechanical Properties of Recycled Glass-Fibre Reinforced Composites; Workshop, University of Belgrade, Serbia.

[6] Sreekumar, P. A.; Thomas, S. P.; Saiter, J. M.; Joseph, K.; Unnikrishnan, G.; Thomas, S. Compos. Part A , 40, 1777, 2009.

[7] Fujihara, K.; Huang, Z. M.; Ramakrishna, S.; Satknanantham, K.; Hamada, H. Biomaterials, 25, 3877, 2004.

[8] Mattila, R. H.; Laurila, P.; Rekola, J.; Gunn, J.; Vallittu, P. K. Acta Biomater. 5, 1639, 2009.

[9] Sabir, M. I.; Li, X. J. Mater. Sci. 44, 5713, 2009

[10] Zairi, F.; Abdelaziz. M. N. Int. J. Sol. Struct. 45, 5220, 2008.

[11] Ravishankar, R.; Chandrashekara, K. Int. J. Mech. Eng. Technol. 4, 197, 2013.

[12] Attel Manjunath. Effect of short glass fiber reinforcement on characteristics of polymer matrix (polycarbonate) - an experimental study, Indian Journal of Mechanical Engineering and Technology, 1 (1), 124-133, 2010.

[13] AbdulKadir G, Ahmet Ö,and Emin Ö. "Experimental investigation of the effect of glass fibres on the mechanical properties of polypropylene (PP) and polyamide 6 (PA6) plastics", Materials \& Design, Vol. 27, Issue 4, pp 316-323, 2006.

[14] Chuan W, Li L. S. and Jin P. O. "Experimental Study on the Corrosion Resistance of GFRPP Rebar in Alkali, Acid and Salt Solution" Advanced Materials Research, Vol. 146-147, pp 1356-1360, 2011.

[15] Ota W. N., Amico, S. C. \& Satyanarayana, K. G. "Studies on the combined effect of injection temperature and fiber content on the properties of polypropylene-glass fiber composites", Composites science and technology, Vol. 65(6), pp. 873-881, 2005.

[16] Rohan Muni Bajracharya, Allan C. Manalo, Warna Karunasena, Kin-tak Lau. "Experimental and theoretical studies on the properties of injection moulded glass fiber reinforced mixed plastics composites", Composites: Part A 84 393-405, 2016.

[17] Ozaki, H.; Nakada, M.; Uzawa, K.; Miyano, Y. Effect of molding condition on flexural strength of textile carbon fiber reinforced polycarbonate laminates. J. Reinf. Plast. Compos. 33, 1893-1901, 2014.

[18] Tanaka, K.; Suzue, M.; Isshiki, S.; Shinohara, M.; Katayama, T. Interfacial and interlaminar shear strength of carbon fiber reinforced polycarbonates made with unidirectional sheets. J. Text. Stud. 42, 82 94, 2016.

[19] Qian, X.; Kravchenko, O.G.; Pedrazzoli, D.; Manas-Zloczower, I. Effect of polycarbonate film surface morphology and oxygen plasma treatment on mode I and II fracture toughness of interleaved composite laminates. Compos. A, 105, 138-149, 2018.

[20] Choi, E.Y.; Kim, J.Y.; Kim, C.K. Fabrication and properties of polycarbonate composites with polycarbonate grafted multi-walled carbon nanotubes by reactive extrusion. Polymer, 60, 18-25, 2015.

[21] Http://www.jushi.com, Email:info@jushi.com

[22] ASTM Standard reference, "D638."

[23] Joong Hee Lee. Polycarbonate/Short Glass Fiber Reinforced Composites - Physico-mechanical, Morphological and FEM Analysis. Journal of REINFORCED PLASTICS AND COMPOSITES, Vol. 27, No. 3/2008,2008. 